\title{
DIAGNOSTICS OF THE ON-VEHICLE SHOCK ABSORBER TESTING
}

\author{
Marek Guzek, Piotr Zdanowicz* \\ Faculty of Transport, Warsaw University of Technology, Warsaw, Poland \\ *E-mail of corresponding author: piotr.zdanowicz@pw.edu.pl
}

\section{Resume}

The practical problems that usually come up during the on-vehicle testing of motor car shock absorbers have been discussed. Results of example tests carried out to the EUSAMA standard procedure were compared to the test results obtained with using newer methods, i.e. the phase angle method and half power bandwidth method (HPBM). The issue of incompatibility of the typical excitation applied by diagnostic suspension testers with one that often occurs in the road conditions has also been raised. It has also been shown that the wear of shock absorbers may affect the value of braking deceleration of cars with ABS (anti-lock braking system) when moving on uneven ground.

The main objective of the work was to assess usefulness and reliability of various diagnostic methods intended for the on-vehicle testing of car shock absorbers.

\section{Article info}

Received 17 September 2020

Accepted 6 November 2020

Online 8 April 2021

\section{Keywords:}

EUSAMA test, phase angle method, half power bandwidth method, experimental tests, simulation tests

\section{Introduction}

The technical condition of automotive shock absorbers is essential for vehicle motion safety and occupants' comfort. With development of the damping components of suspension systems, newer and better methods of diagnosing such parts are continuously sought. The "on-vehicle" tests are particularly useful thanks to their low costs and short duration time. Predominantly, "forced vibration tests" are used for this purpose [1-2]. At present, efforts are made in Europe to adopt an identical (standard) vibration excitation method for all the shock absorber testers. As one of the peculiarities of such a method, the stroke of the tester vibration plate is to be constant, equal to e.g. $6 \mathrm{~mm}$, as it is in the case of the EUSAMA machines [1-7]. Unfortunately, such testers, which are the most popular, suffer from a major drawback: the final test result strongly depends on the tire inflation pressure, sprung mass, sliding friction in the suspension system, test conditions, and tester characteristics [1-2, 4, 6-8].

In consideration of the above, the authors decided to verify the reliability and usefulness of the phase angle method [8] and the half power bandwidth method (HPBM) [4] in relation to the classic EUSAMA test, the newer methods are based upon. This was the main objective of this work. At this opportunity, the issue of incompatibility of the typical excitation applied by diagnostic suspension testers with one that often occurs in the road conditions has also been addressed (see also [7]). It has been shown as well that the shock absorbers wear may affect the process of braking a car with the ABS when moving on uneven ground, which has been highlighted by e.g. the authors of [5].

\section{Evaluation of the suspension system damping impact on the final results of the rig testing of shock absorbers by various methods}

Usefulness and reliability of the diagnostic methods under consideration, used for the on-vehicle testing of motor car shock absorbers, was assessed on the grounds of measurement results obtained with using a prototype tester TUZ-1/E. A short description of the performed tests is presented in Table 1 . In every test, a sinusoidal input was applied with a constant amplitude of $3 \mathrm{~mm}$ and a frequency declining from about $25 \mathrm{~Hz}$ to zero at a rate of $1 \mathrm{~Hz} / \mathrm{s}$; the outputs recorded were time histories of the vertical force under the tester vibration plate and of the vertical displacement and acceleration of the plate (necessary to eliminate the distorting impact of the inertial force of this exciter component, see also [6]). All the tests were carried out for the rear suspension system of an Opel Astra II (G) Van, in which the viscous damping was changed stepwise by applying 8 known damping levels $\gamma$, varying between 0.131 and 0.511 (see Table 2). Such tests were repeated twice, with the tire 
Table 1 Description of performed tests

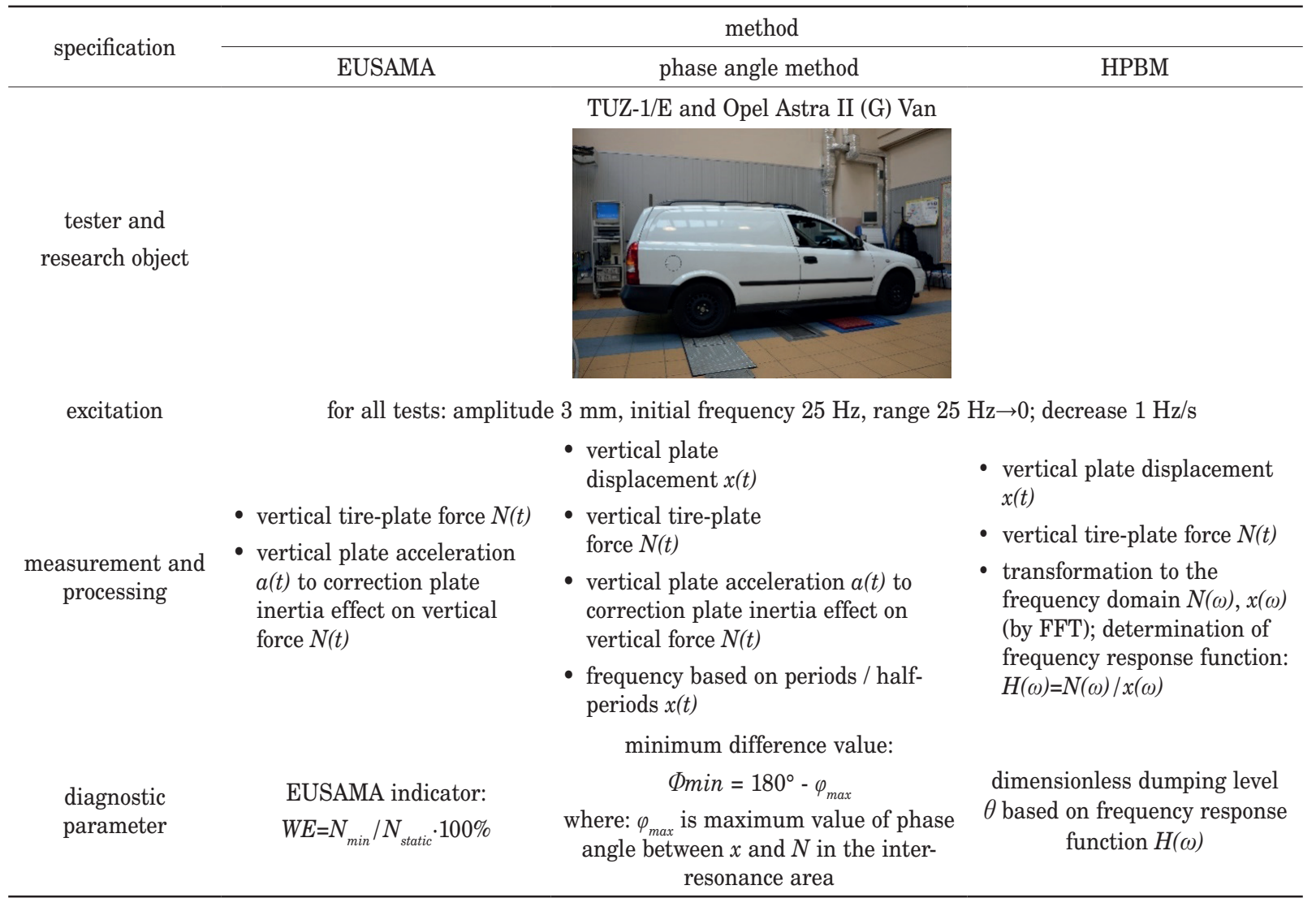

Table 2 Tested car and tests' conditions

\begin{tabular}{|c|c|c|}
\hline \multicolumn{3}{|c|}{$\begin{array}{c}\text { C-class car Opel Astra II (G) Van, car mass } 1090 \mathrm{~kg}, \\
\text { "quarter" car sprung mass: } 160 \mathrm{~kg} \text {, "quarter" car unsprung mass: } 35 \mathrm{~kg}\end{array}$} \\
\hline \multicolumn{3}{|c|}{ rear suspension } \\
\hline \multicolumn{3}{|c|}{$\begin{array}{c}\text { the variable damping level was achieved by using (by replacing the original) a shock absorber with a variable dampir } \\
\text { characteristics }\end{array}$} \\
\hline car state case: & tire pressure $p[\mathrm{MPa}]$ & sliding friction $A t s_{1}[\mathrm{~N}]$ \\
\hline - nominal & 0.21 & 40 \\
\hline - reduced tire pressure & 0.1 & 40 \\
\hline - increased sliding friction & 0.21 & 250 \\
\hline
\end{tabular}

inflation pressure being reduced from nominal $0.21 \mathrm{MPa}$ to $0.1 \mathrm{MPa}$ and the sliding friction in the suspension system being raised from $40 \mathrm{~N}$ (nominal value) to $250 \mathrm{~N}$ (value obtained by additional sliding friction damper in the suspension system; this situation may correspond to other cases of suspension design solutions, where the level of sliding friction in the suspension may be higher e.g. in suspensions with MacPherson struts or leaf springs); all the other vehicle parameters remained at their nominal levels.

In result of an analysis of results of the EUSAMA test (Figure 1), which were determined from the normal reaction at the tire-exciter contact point (instead of the force measured under the vibration plate, see also [6]), with the main test phase being extended to $25 \mathrm{~s}$, the following has been found:
- The EUSAMA indicator value vs suspension damping curves have degressive shapes.

- For the car, with nominal sliding friction and standard tire inflation pressure, the diagnostic parameter changed here in a very narrow range (from 0 to about $20 \%$ ).

- The growth of the sliding friction in the suspension system by $210 \mathrm{~N}$ could cause here the final test results to be overestimated by as much as 20 percentage points.

- The reduction of the tire inflation pressure from $0.21 \mathrm{MPa}$ to $0.1 \mathrm{MPa}$ could cause a considerable overestimation of the EUSAMA indicator value (even by more than 30 percentage points in this case).

The obtained tire pressure effect qualitatively 


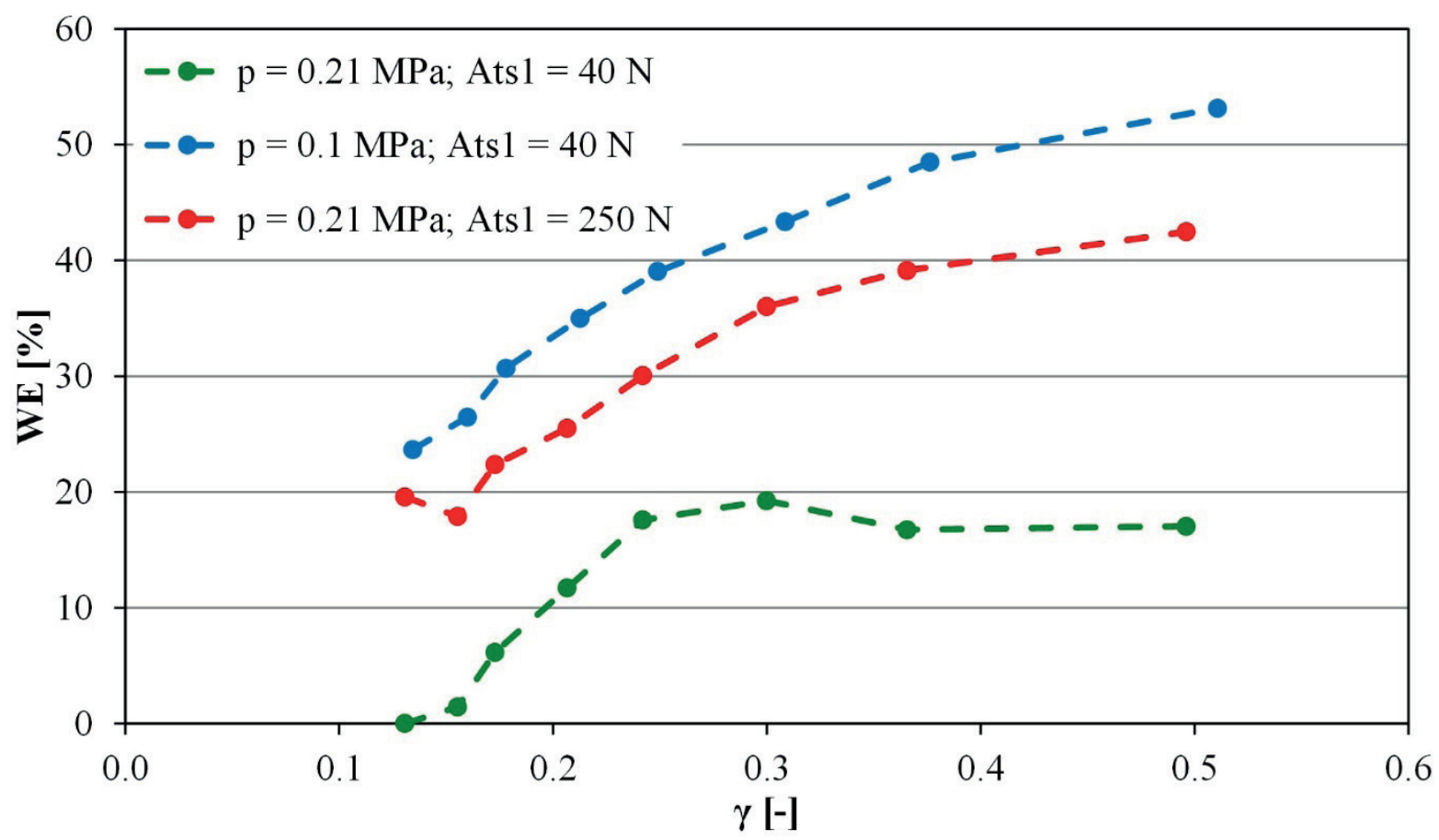

Figure 1 Example results of diagnostic testing of the rear suspension system of an Opel Astra II (G) Van with using the EUSAMA method, for various levels of viscous damping in the shock absorber, at a nominal and reduced tire inflation pressure ( $p=0.21 \mathrm{MPa}$ and $p=0.1 \mathrm{MPa}$, respectively) and a nominal and raised sliding friction in the suspension system $\left(\right.$ Ats $_{1}=40 \mathrm{~N}$ and Ats ${ }_{1}=250 \mathrm{~N}$, respectively)

confirms results known from the literature (see e.g. [1, 8]). The distorting effect of the sliding friction on the test result was presented in [2, 7], as well.

As mentioned in the introduction, the weaknesses of the EUSAMA method mentioned above are the source of search for the new methods. One of them is the phase angle method proposed in [8]. The evaluation criterion is the phase angle $\Phi$ between the input excitation (plate displacement) and the response in the form of a force in the tire-plate contact. Results of analogous tests for this method are shown in Figures 2 and 3. Figure 2 shows an example of histories of the phase angle value as a function of frequency for the test with a nominal shock absorber in very good condition $(\gamma=0.28)$. Figure 3 shows the criteria values for the assessment of the shock absorber wear - the minima $\Phi_{\min }$ of the phase angle for different levels of damping in the tested rear suspension.

When usefulness of the phase angle method was assessed, the following was observed:

- At high values of the viscous damping and sliding friction in the suspension system, a minimum of the phase shift angle between the excitation and the tire-exciter contact force may be hardly noticeable or it does not exist at all (Figure 2).

- The minimum phase shift angle value vs suspension damping curves have the degressive shapes (Figure 3).

- For the car with nominal sliding friction and standard tire inflation pressure, the diagnostic parameter changed here in quite a wide range (from $0.4 \mathrm{rad}$ to about $1.2 \mathrm{rad}$, see Figure 3).

- Reduction of the tire inflation pressure from
$0.21 \mathrm{MPa}$ to $0.1 \mathrm{MPa}$ did not cause in this case any considerable changes in the final test results (Figure 3).

- Increase of the sliding friction in the suspension system for $210 \mathrm{~N}$ caused here the final test results to be overestimated by as much as $0.7 \mathrm{rad}$ (Figure 3 ).

- During the test, the frequency drops to zero. However, assessment of the phase angle in the lowfrequency area (here below $5 \div 7 \mathrm{~Hz}$, see Figure 2), due to the highly distorted signals in this frequency range, turned out to be impossible to perform under the real measurement conditions (presence of the higher frequency components, as well as slack and friction in the system, resulted in local extremes, e.g. double maxima, minima, or transitions through the mean value level; as a result, it was not possible to determine the characteristic points on the waveforms and to determine the phase angle).

Summing up, this method shows significant advantages over the classic EUSAMA test (slight influence of tire pressure - see also [1, 8]), but unfortunately, influence of the sliding friction on the test result remains. It has also been shown that there may be situations when determination of the diagnostic parameter value may be impossible (e.g. with very high and low suspension damping).

The third considered method is the method proposed in [4] - the half power bandwidth method (HPBM). Here, too, analysis is performed in the frequency domain. The diagnostic parameter is the dimensionless damping coefficient $\theta$ determined based on the spectral function of the force response in the plate-tire contact in relation 


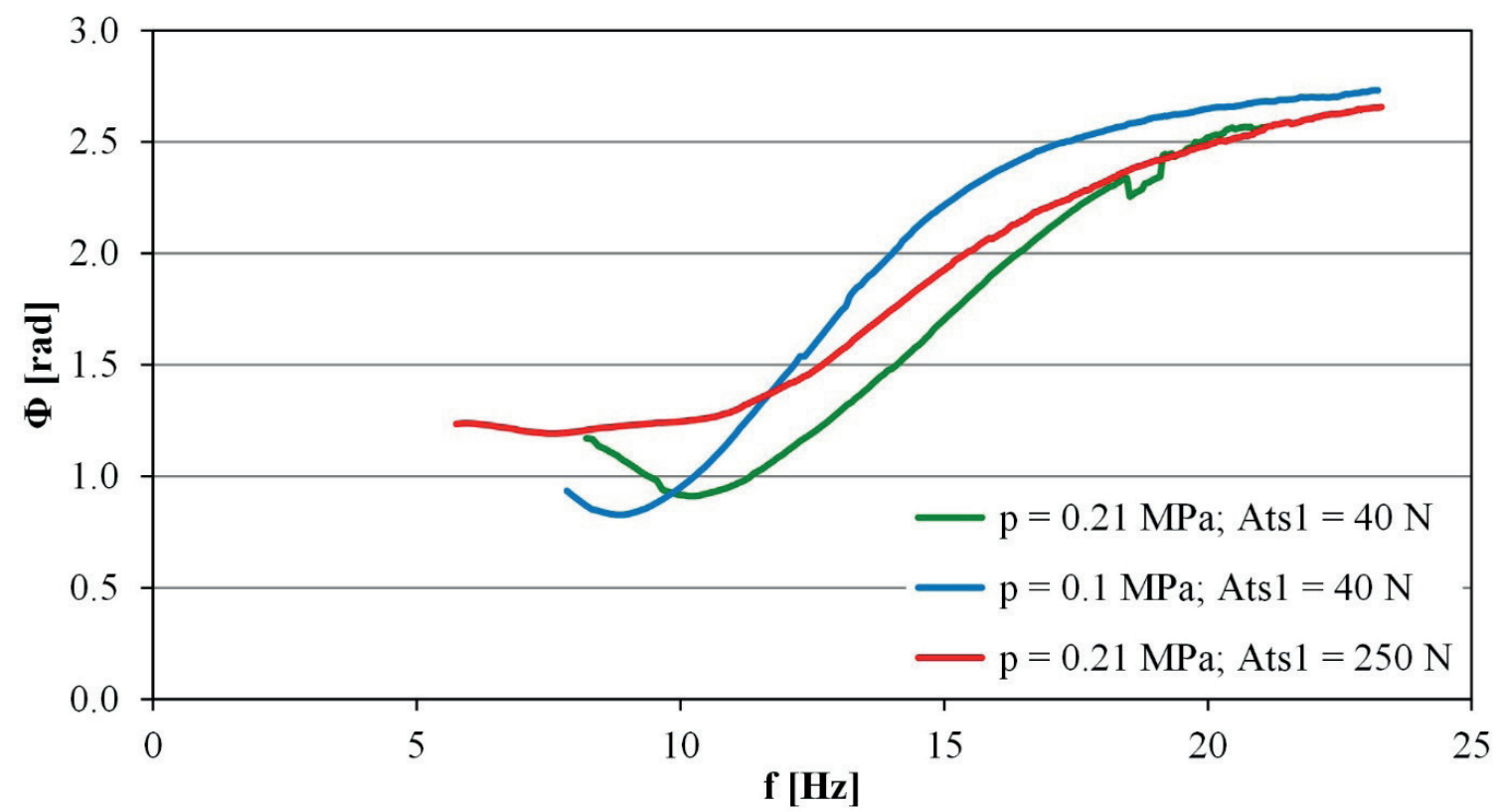

Figure 2 Example results of diagnostic testing of the rear suspension system of an Opel Astra II (G) Van by the phase angle method, for a shock absorber in a very good condition, at a nominal and reduced tire inflation pressure ( $p=0.21 \mathrm{MPa}$ and $p=0.1 \mathrm{MPa}$, respectively) and a nominal and raised sliding friction in the suspension system (Ats $s_{1}=40 \mathrm{~N}$ and $A t s_{1}=250 \mathrm{~N}$, respectively)

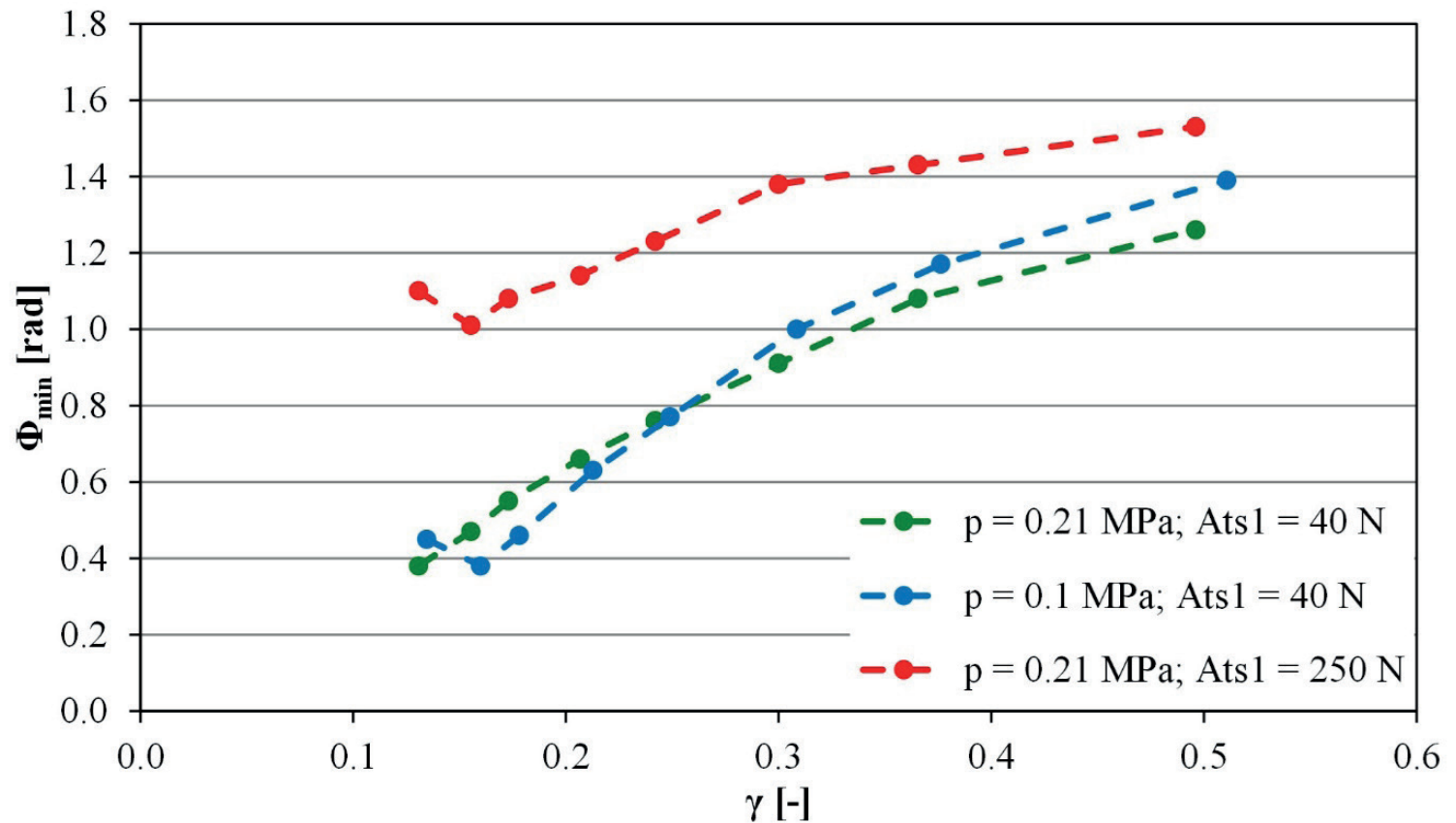

Figure 3 Example results of diagnostic testing of the rear suspension system of an Opel Astra II (G) Van by the phase angle method, for various levels of viscous damping in the shock absorber, at a nominal and reduced tire inflation pressure $(p=0.21 \mathrm{MPa}$ and $p=0.1 \mathrm{MPa}$, respectively) and a nominal and raised sliding friction in the suspension system $\left(\mathrm{Ats}_{1}=40 \mathrm{~N}\right.$ and $\mathrm{Ats} \mathrm{s}_{1}=250 \mathrm{~N}$, respectively)

to the plate displacement. In the presented research, evaluation of the dimensionless damping coefficient using the HPBM method, the force signal recorded on the test rig was used (without eliminating the distorting impact of the force of inertia of the tester vibration plate). Based on appropriate measurements and calculations, the following was ascertained in this case (see Figure 4):

- Parameter $\theta$ quite well describes the actual condition of the shock absorber under test, except for excessive damping level (i.e. if $\gamma<0.25$ ).

- $\quad$ For the high damping levels $(\gamma>0.25)$, the final results were markedly underestimated.

- The HPBM proved in this case to be rather insensitive to variations in the tire inflation pressure.

- Increase of the sliding friction in the suspension system for $210 \mathrm{~N}$ caused here the final test results to be clearly overestimated (even by more than $20 \%$ ). 


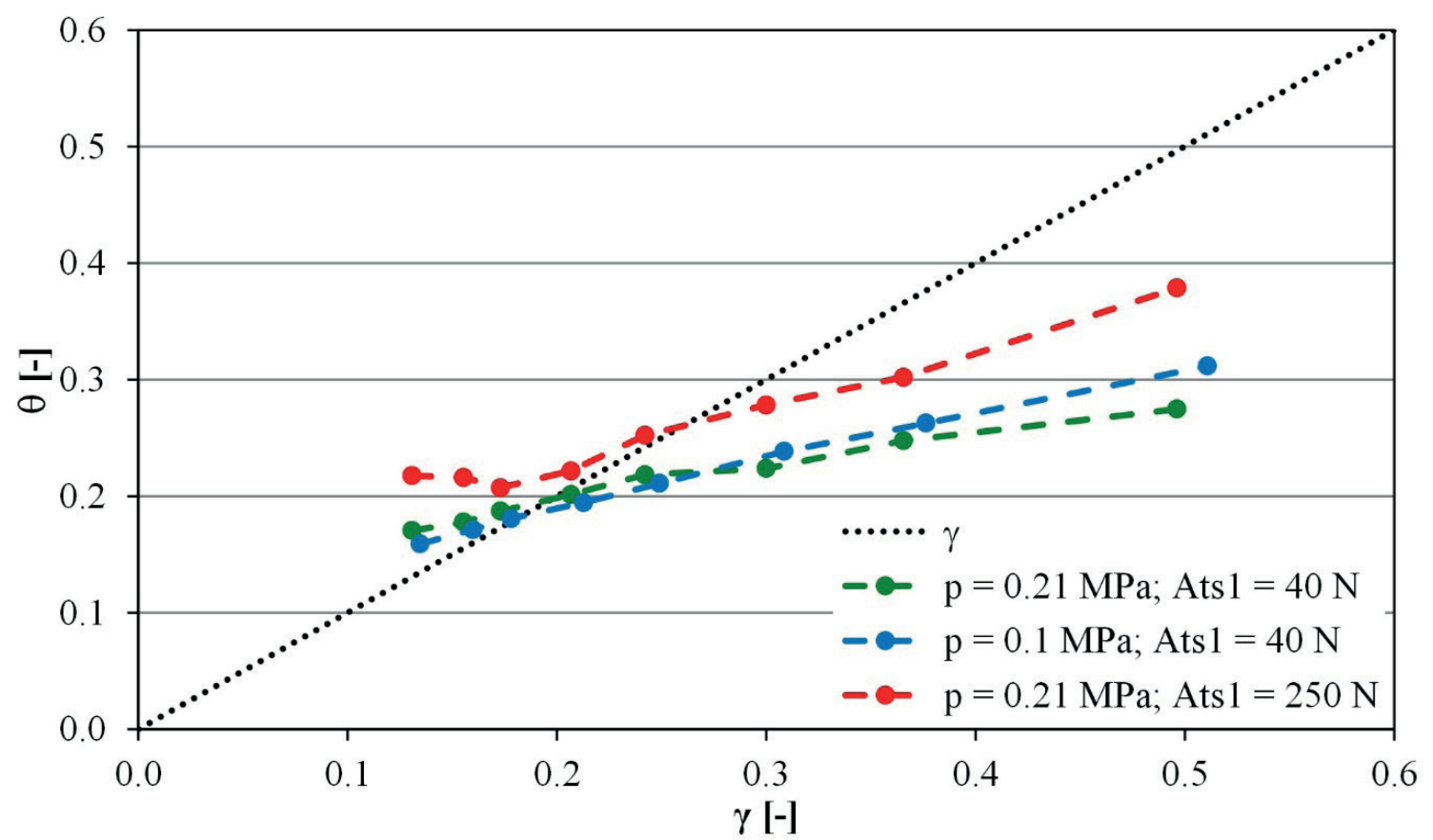

Figure 4 Example results of diagnostic testing of the rear suspension system of an Opel Astra II (G) Van by the half power bandwidth method (HPBM), for various levels of viscous damping in the shock absorber, at a nominal and reduced tire inflation pressure ( $p=0.21 \mathrm{MPa}$ and $p=0.1 \mathrm{MPa}$, respectively) and a nominal and raised sliding friction in the suspension system (Ats ${ }_{1}=40 \mathrm{~N}$ and Ats ${ }_{1}=250 \mathrm{~N}$, respectively)

Summing up, based on the results shown, in the case of the HPBM method, we can talk about a slight influence of the tire pressure (see also [4]) and a significant influence of sliding friction. In addition, the method gave good results only in a narrow range of the viscous damping low levels.

3 Comparison, by simulation, of selected operating parameters of the motor car suspension system in a typical diagnostic test and in road conditions

To depict the differences in the vehicle suspension system functioning in a diagnostic test and real road operation conditions, simulation test results were used. This work was done on a front "quarter" of the Isuzu D-max motor vehicle. Although the two transverse arms were provided in the front suspension system of this vehicle, the system was characterized by relatively strong sliding friction force $\left(A t s_{1}=158 \mathrm{~N}\right)$, typical for passenger cars with MacPherson struts.

In the simulations, a non-linear, experimentally verified "quarter-car" model was used (see Figure 5), where the sliding friction in the suspension system and smoothing properties of the tires and also tire separation from the ground ("lift-off") were taken into account (mathematical model - see also [2, 7]). Most of the model parameters had been previously identified in rig tests (main parameters - see Table 3). Only the shock absorber and tire damping were described in a linear form. The viscous damping in the suspension system was changed for the dimensionless coefficient of damping $\gamma$ to vary from 0 to 0.5 in steps of 0.02 and the tire damping adopted was based on literature data.

Figure 6 shows results of a series of simulations in which the excitation was applied in a form analogous to the EUSAMA test. These are the obtained maximum and minimum values of viscous damping forces as a function of the EUSAMA indicator value (denoted here by "WE"). Due to the low amplitude (3 $\mathrm{mm}$ ) and moderate frequency $(10 \div 20 \mathrm{~Hz})$ of excitation, at which the final test results are determined, rather low suspension deflection rates are obtained in the EUSAMA test, even if the shock absorbers under tests are worn out very badly. This situation occurs especially when the sliding friction in the suspension is sufficiently high. During such a diagnostic test, the maximum absolute values of the viscous damping force (meant as the force reduced to the vertical axis in the "quarter-car" model) very seldom exceed $500 \mathrm{~N}$, even if the shock absorber condition is very good. One has to be aware of the fact that in the conditions where the EUSAMA test result is good, i.e. the EUSAMA indicator value is higher than $40 \%$, the amplitude of the viscous damping force only slightly exceeds the value of the force of sliding friction $F s_{1 \min / \max }$ in the suspension system. If, however, the half-cycle average values are used then the value of the viscous damping force amplitude may turn out to be markedly lower than the value of the sliding friction force. Hence, a statement may be made that the final result of the diagnostic EUSAMA shock absorber testing depends to a considerable degree on the frictional resistance in the suspension system (see also [7]). 
a)

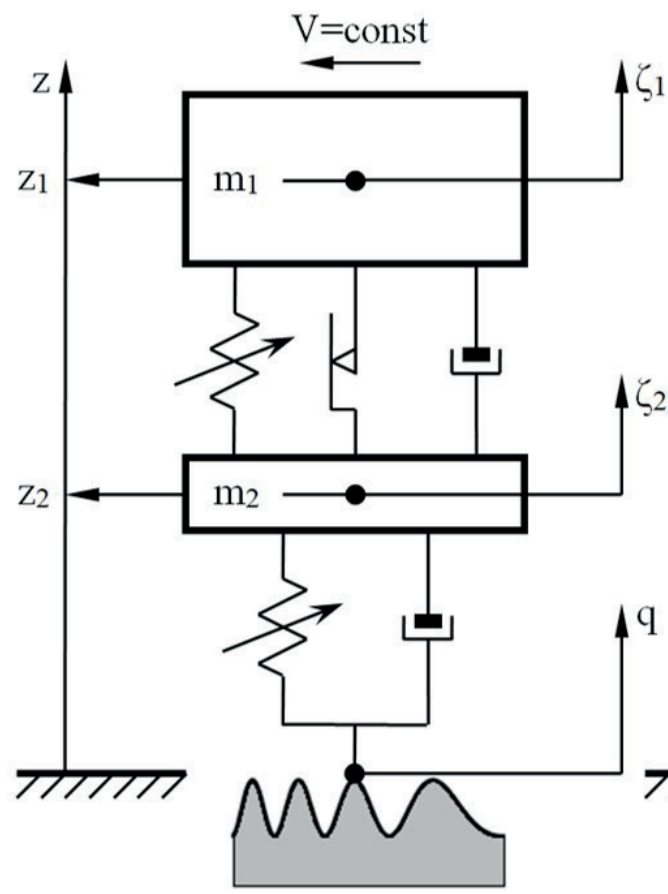

b)

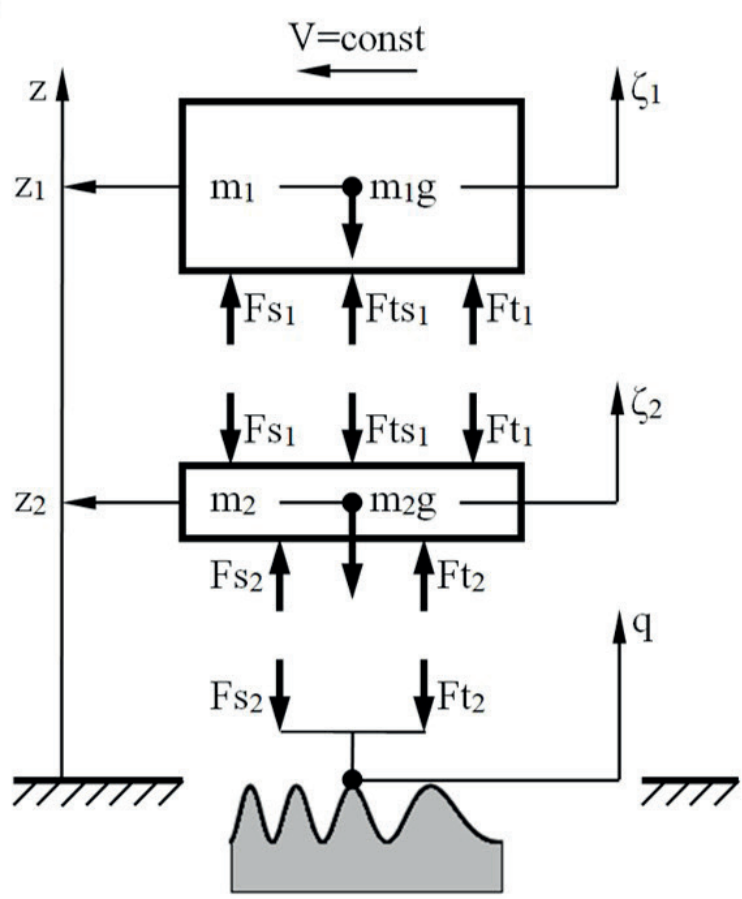

Figure 5 Nonlinear "quarter-car" model with dry friction in the suspension system: a) general structure; b) system of forces; $F_{s_{1}}$ - elasticity force in the suspension system; $F_{s_{2}}$ - elasticity force in the tire; Ft - viscous damping force in the suspension system; $F t_{2}$ - damping force in the tire; Fts $s_{1}$ - sliding friction force in the suspension system; $m_{1}$ - sprung mass; $m_{1} g$ - weight of the sprung parts; $m_{2}$ - unsprung mass; $m_{2} g$ - weight of the unsprung parts; $q$ - input displacement; $z_{1}$ - coordinate of the centre of the sprung mass; $z_{2}$ - coordinate of the centre of the unsprung mass; $\zeta_{1}$ - vertical axis of the system attached to the sprung mass; $\zeta_{2}$ - vertical axis of the system attached to the unsprung mass

Table 3 Model and simulation parameters

\begin{tabular}{cc}
\hline vehicle: & Isuzu D-Max, mass: $3011 \mathrm{~kg}$ \\
\hline tested vehicle part: & front suspension \\
masses: & $m_{1}=578 \mathrm{~kg}, m_{2}=69.5 \mathrm{~kg}$
\end{tabular}
suspension and tire parameters: linear tire damping characteristic, for the presented test the linear shock-absorber damping characteristic was assumed; values and characteristics identified on real car

variable: dimensionless damping levels $\gamma$, at range of $0 \div 0.5(\mathrm{c}=0 \div 4531 \mathrm{Ns} / \mathrm{m})$

simulation condition:

car velocity: $25 \mathrm{~m} / \mathrm{s}(90 \mathrm{~km} / \mathrm{h})$, excitation (road irregularities): EUSAMA tester sinusoidal signal or C class road by ISO [9]

(taking into account the smoothing properties of the vehicle tires)

Figure 7 shows the simulation results for the vehicle motion at a speed of $90 \mathrm{~km} / \mathrm{h}$ on an average road (pavement category $\mathrm{C}$, according to [9]). For the same vehicle, the suspension deflection rates will be much higher. In such suspension system operation conditions, the peak-to-valley values of the viscous damping forces in the shock absorber markedly increase (linearly, in rough terms) with growing relative damping in the suspension system. For the nominal values of vehicle parameters $(\gamma \approx 0.3)$, the sliding friction resistance made here merely about $10 \%$ of the viscous damping force in the suspension system and did not have any significant impact on the energy dissipation process of the vertical vehicle vibration. It can also be clearly seen that for the simulation of vehicle motion on an average road (pavement category $\mathrm{C}$ ), the damping force generated by a nominal shock absorber would be three times as strong as that generated in the EUSAMA test (see also [7]). 


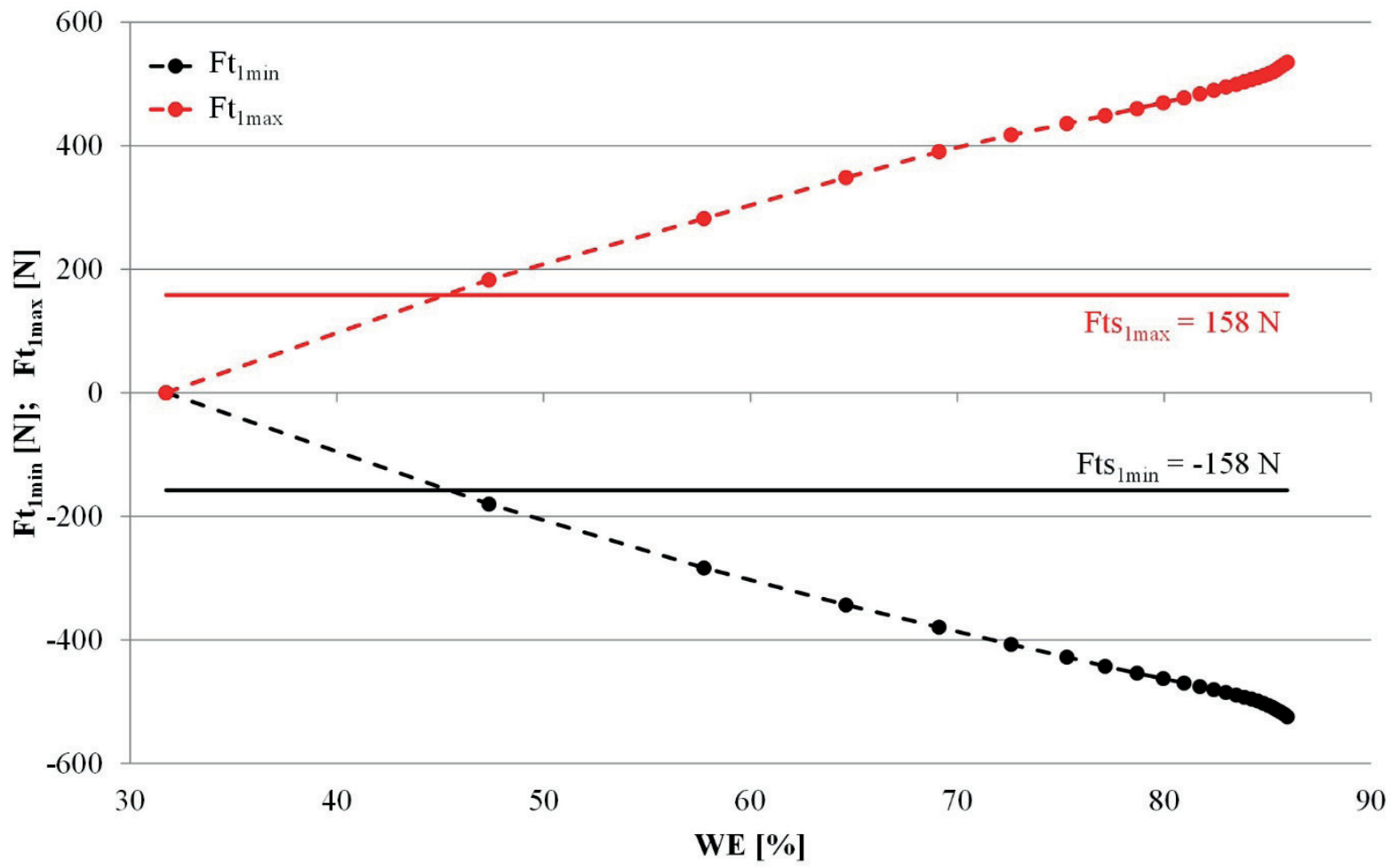

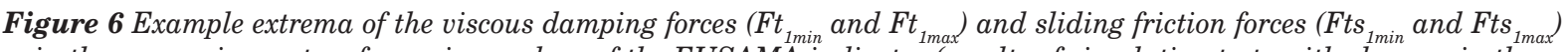
in the suspension system for various values of the EUSAMA indicator (results of simulation tests with changes in the technical condition of the shock absorber in the front "quarter" of the Isuzu D-max motor vehicle)

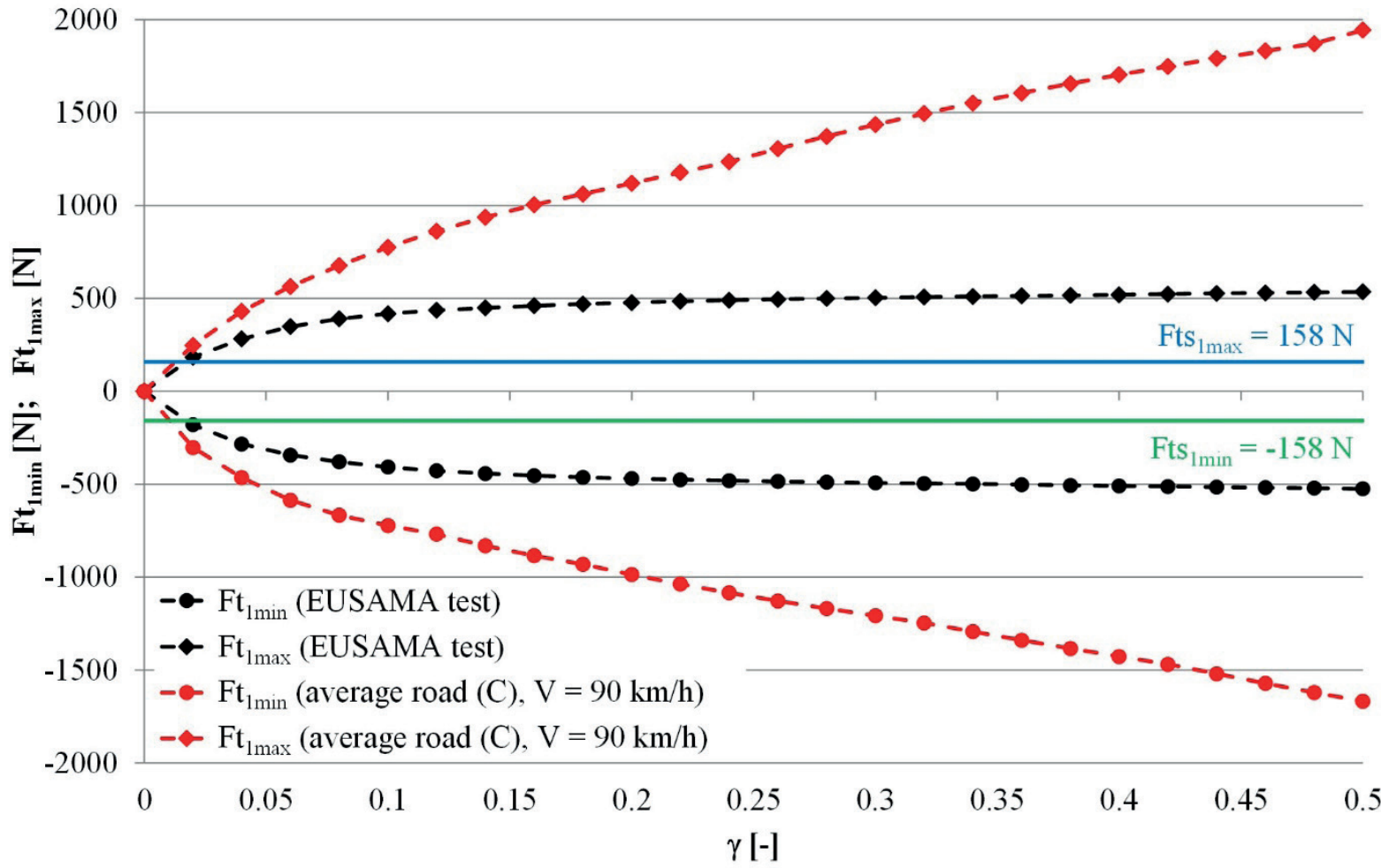

Figure 7 Comparison of the example extrema of the viscous damping forces $\left(F t_{1 \min }\right.$ and $F t_{1 \text { ma }}$ ) and sliding friction forces

(Fts 1min and $F t s_{1 \text { max }}$ in the vehicle suspension system at various values of the dimensionless damping coefficient in the suspension system (results of a simulation of the EUSAMA test and a test of vertical vibration of the vehicle on an average road (C pavement category) for the front "quarter" of the Isuzu D-max motor vehicle) 


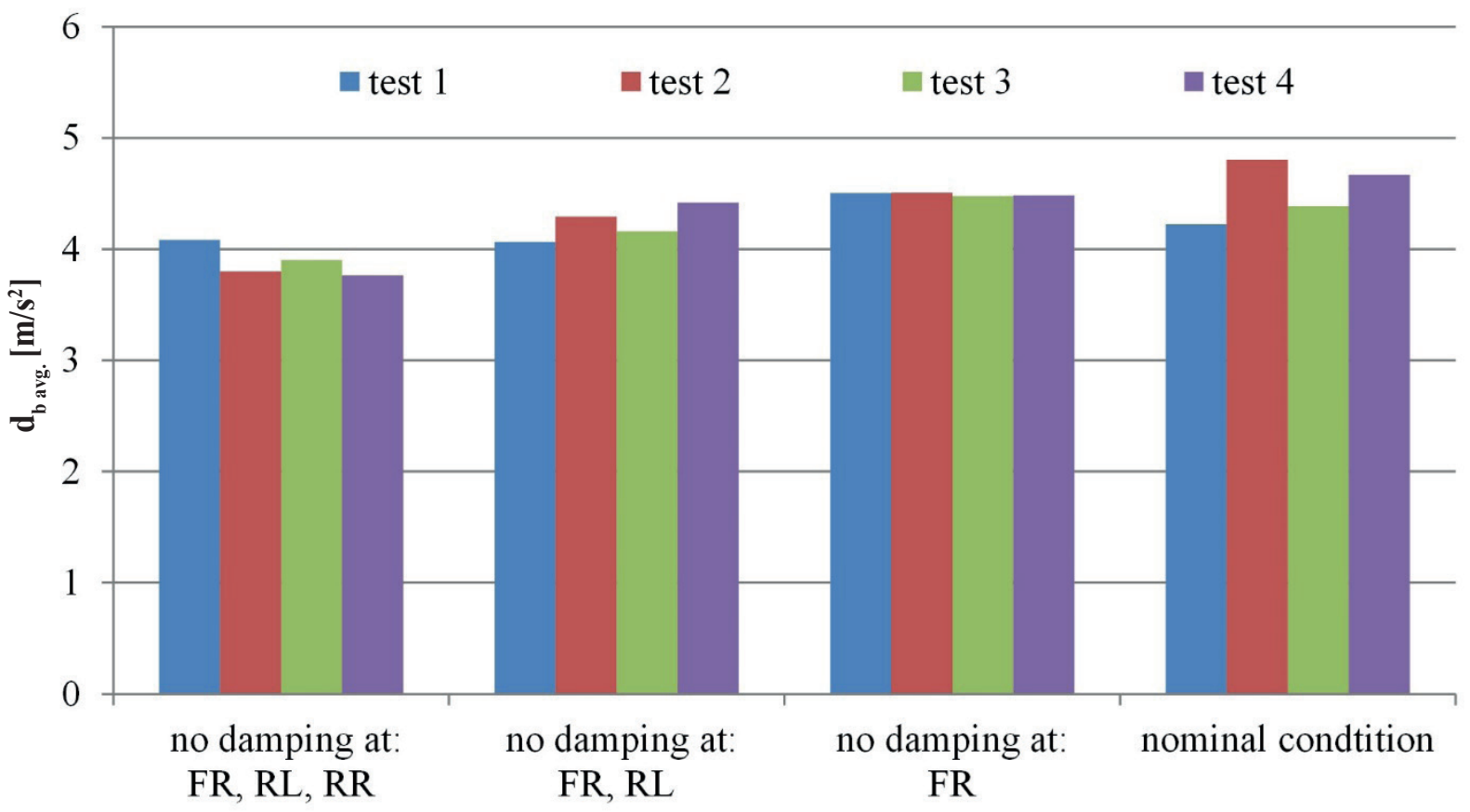

Figure 8 Comparison of the average braking deceleration values recorded during the tests of an Opel Agila car on a test track section representing a double-track uneven tramway crossing, with various levels of the viscous damping in the car suspension system (FR - front right; $R L$ - rear left; $R R$ - rear right)

\section{Experimental evaluation of the impact of shock absorber wear on vehicle braking deceleration}

Since the literature data (e.g. those provided in [5]) show a marked impact of the shock absorber condition on the course of the vehicle braking process, a decision was made to re-verify this information. With this end in view, 16 experimental tests were carried out on an Opel Agila 1.2 Twinport car provided with ABS (car mass ca. $1175 \mathrm{~kg}$ ).

The tests of vehicle braking from an initial speed of about $50 \mathrm{~km} / \mathrm{h}$ were carried out on a test track section representing a double-track tramway crossing with rails protruding about $20 \mathrm{~mm}$ above the road surface. The dry road pavement was made of concrete slabs, which were unevenly laid and, in consequence, additional vibration typical for crossings of this kind was excited.

The tests were carried out by a decelerometer CL-170 and with recording the braking deceleration and brake pedal force. This force deliberately exceeded the acceptable maximum so that the driver had a limited control over the course of the braking process. The instrument readings, subject to the final assessment, were the average braking deceleration values, determined for the main phase of the braking process. Every test was repeated three times, and 4 tests were carried out within each test series, during which the following vehicle options were examined:

- vehicle in its nominal condition;

- vehicle with no viscous damping in the front right (FR) wheel suspension system;

- vehicle with no viscous damping in the front right
(FR) and rear left (RL) wheel suspension system; - vehicle with no viscous damping in the front right $(\mathrm{FR})$, rear left $(\mathrm{RL})$, and rear right $(\mathrm{RR})$ wheel suspension system.

When analyzing the measurement results presented in Figure 8, one can notice a moderate impact of the viscous damping in the vehicle suspension system on the vehicle braking deceleration value. For the vehicle with 3 shock absorbers damaged, the braking deceleration obtained was lower by about $0.5 \mathrm{~m} / \mathrm{s}^{2}$ to $1 \mathrm{~m} / \mathrm{s}^{2}$ in comparison to that obtained by the vehicle in its nominal condition.

\section{Recapitulation and conclusions}

The conducted research confirmed the information mentioned in the literature about the disruptive influence of the tire pressure $[1,8]$ and sliding friction $[2,7]$ on results of the standard diagnostic tests using the EUSAMA method. The presented results also show that the other analyzed methods (the phase angle method, HPBM) are less sensitive to the abovementioned disturbances (in particular, lower influence of tire pressure), but also have their drawbacks. Among the diagnostic shock absorber testing methods discussed herein, the most promising one seems to be the phase angle method. On the other hand, the poorest opinion is deserved by the half power bandwidth method (HPBM), which intrinsically may only be used for estimation of the dimensionless damping coefficient in linear systems with one degree of freedom and with a low energy dissipation level. For the reliability and, simultaneously, 
usefulness of the EUSAMA test to be raised, this method needs improving. A modification has already been proposed by one of the co-authors of this study, but it cannot be disclosed at present because of a patent application planned.

In all the methods, there is a problem because the excitation applied on a diagnostic test stand is incompatible with the one that often occurs in the real vehicle operation conditions. While the sliding friction in the suspension system can, so to say, "substitute" for the viscous damping during the diagnostic shock absorber test (making the test result satisfactory), it will definitely be insufficient to disperse the vertical vehicle vibration on a road.

The degree of shock absorber wear may have an impact on the course of the vehicle braking process, especially when the vehicle is provided with an ABS and is moving on an uneven ground.

\section{References}

[1] STANCZYK, T. L., JURECKI, R. Comparative analysis of testing methods of hydraulic shock absorbers / Analiza porownawcza metod badania amortyzatorow hydraulicznych (in Polish). Zeszyty Naukowe Instytutu Pojazdow / Proceedings of the Institute of Vehicles [online]. 2014, 4(100), p. 25-45 [accessed 2020-08-07]. ISSN 1642-347X. Available from: http://www.zeszyty.simr.pw.edu.pl/artykuly/zn4(100)2014/025_045.pdf

[2] ZDANOWICZ, P. Assessment of the condition of vehicle's shock absorbers with taking into account the dry friction in the suspension system / Ocena stanu amortyzatorow pojazdu z uwzglednieniem tarcia suchego w zawieszeniu (in Polish). Doctoral dissertation. Warsaw: Warsaw University of Technology, Faculty of Transport, 2012.

[3] Recommendation for a performance test specification of an 'on-car' vehicle suspension testing system. Publication TS 02 76. Nottingham: European Shock Absorber Manufacturers Association, 1976.

[4] CALVO, J. A., DIAZ, V., SAN ROMAN, J. L. Establishing inspection criteria to verify the dynamic behaviour of the vehicle suspension system by a platform vibrating test bench. International Journal of Vehicle Design [online]. 2005, 38(4), p. 290-306 [accessed 2020-08-07]. ISSN 0143-3369. Available from: https://doi.org/10.1504/ IJVD.2005.007623

[5] CALVO, J. A., DIAZ, V., SAN ROMAN, J. L., GARCIA POZUELO, D. Influence of shock absorber wearing on vehicle brake performance. International Journal of Automotive Technology [online]. 2008, 9(4), p. 467-472 [accessed 2020-08-07]. ISSN 1229-9138. Available from: https://doi.org/10.1007/s12239-008-0056-z

[6] LOZIA, Z., ZDANOWICZ, P. Simulation assessment of the impact of inertia of the vibration plate of a diagnostic suspension tester on results of the EUSAMA test of shock absorbers mounted in a vehicle. IOP Conference Series: Materials Science and Engineering [online]. 2018, 421(2) [accessed 2020-08-07]. ISSN 1757-899X. Available from: https://iopscience.iop.org/article/10.1088/1757-899X/421/2/022018/pdf

[7] ZDANOWICZ, P. Comparative assessment of vertical vibrations of a vehicle on the road and during the EUSAMA test. IOP Conference Series: Materials Science and Engineering [online]. 2018, 421(2) [accessed 2020-08-07]. ISSN 1757-899X. Available from: https://iopscience.iop.org/article/10.1088/1757-899X/421/2/022045/pdf

[8] TSYMBEROV, A. An improved non-intrusive automotive suspension testing apparatus with means to determine the condition of the dampers. SAE Technical Paper [online]. 1996, 960735 [accessed 2020-08-07]. ISSN 0148-7191. Available from: https://doi.org/10.4271/960735

[9] 1995 ISO 8608 Mechanical vibration. Road surface profiles. Reporting of measured data. 